\title{
Analisis Tentang Hubungan Antara Cerpen Reaching For The Sky Karya Mitchell Waldman dengan Teori Strukturalisme Genetik
}

\author{
Oryza Nurmartanti \\ Fakultas Ilmu Budaya Universitas Diponegoro \\ cha_tie82@yahoo.co.id
}

\begin{abstract}
The journal entitled "Analysis of the Relationship between Reaching For The Sky Short Story and Genetic Structural Theory" aims to describe the genetic structuralistic relationship shown in the study of Reaching For The Sky short stories. This research uses descriptive analysis method by using literary sociology analysis techniques. Short Story Reaching For The Sky is an interesting to be chosen because it is thought to show the relationship between structuralism theory and social inequality.

The results showed that the short story Reaching For The Sky by Mitchell Waldman is work that is full of criticism about social class inequality that occurs in Brooklyn, New York, USA. This short story besides carrying the theme of social class, can also be examined more deeply using the theory of Genetic Structuralism. This can be achieved because between the short story and the author, there is a very close relationship. Can be identified through the author's background and what is in the short story. Characters, settings, story lines, enough to represent the correlation of short stories, authors and theories that support the link between the short storyline and genetic structuralism. Among these are: facts of humanity, collective subjects, worldview, structuration and dialectics of understanding.
\end{abstract}

Keywords: Anallysis; genetics structuralism; social discrimination; short story Reaching For The Sky.

\section{Intisari}

Jurnal berjudul "Analisis Tentang Hubungan Antara Cerpen Reaching For The Sky dengan Teori Strukturalisme Genetik" ini bertujuan untuk mendeskripsikan hubungan strukturalistik genetik yang ditunjukkan dalam kajian cerpen Reaching For The Sky. Metode deskriptif analisis adalah acuan penelitian dengan menggunakan teknik analisis sosiologi sastra. Cerpen Reaching For The Sky menarik untuk dipilih sebagai objek analisis karena diduga menunjukkan adanya hubungan teori strukturalisme dengan ketimpangan sosial.

Hasil penelitian menunjukkan bahwa cerpen Reaching For The Sky karya Mitchell Waldman adalah sebuah karya yang sarat akan kritik tentang ketimpangan kelas sosial yang terjadi di Brooklyn, New York, AS. Cerpen ini selain mengusung tema tentang kelas sosial, dapat pula dikaji lebih mendalam menggunakan teori Strukturalisme Genetik. Hal ini dapat dicapai karena antara cerpen dan pengarangnya, terdapat suatu keterkaitan yang sangat erat. Dapat di identifikasi melalui latar belakang pengarang dan apa saja yang ada didalam cerpen tersebut. Tokoh-tokoh, setting, alur cerita, cukup mewakilkan akan adanya korelasi cerpen, pengarang dan teori-teori yang mendukung adanya keterkaitan antara jalan cerita cerpen dan strukturalisme genetik. Bahasan utuk teori tersebut yaitu: fakta kemanusiaan, subjek kolektif, pandangan dunia, strukturasi, dialektika pemahaman.

Kata kunci: Analisis; stukturalisme genetik; ketimpangan sosial; Cerpen Reaching For The Sky. 
Oryza Nurmartanti, Analisis Tentang Hubungan Antara Cerpen Reaching For The Sky Karya Mitchell Waldman dengan Teori

Strukturalisme Genetik

\section{Pendahuluan}

Karya sastra adalah cerminan dari kehidupan manusia. Adanya kehidupan manusia, memunculkan beberapa aspek, termasuk diantaranya adalah seni sastra dan seni budaya. Sepanjang perkembangan peradaban dan sejarah, karya seni sastra merupakan sajian kehidupan dan 'kehidupan' terdapat adanya fakta sosial, walaupun sebuah karya sastra merupakan imitasi dari keberadaan alam dan eksistensi manusia. (Wellek dan Warren, 1977:109).

Goldmann dalam Faruk (2010:56) menyatakan sebuah teori strukturalisme genetik, sebagai perwujudan sebuah struktur dari karya sastra. Namun, struktur juga bukan sesuatu yang tetap, tetapi merupakan realisasi dari masa lalu kemudian menjadi sejarah yang sampai saat ini masih eksis, perjalanan menuju strukturasi, destrukturasi yang menjadi dasar dan diselami oleh pecinta karya sastra yang bersangkutan. Sebagai teori, Strukturalisme genetik merupakan teori mutlak dalam melihat suatu realita.

Karya sastra bersifat fiktif, imajiner dan erat dengan ideologi pengarang. Salah satunya adalah cerpen. Cerpen atau cerita pendek adalah suatu karya sastra itu sendiri merupakan gambaran kehidupan penulis cerpen dan kehidupan sosialnya. Fenomena yang terjadi dilingkungan sekitar yang dihadapi, yang melingkupi hidup pengarang, pendapat dan kritikan pengarang, akan terungkap menjadi satu dalam sebuah tulisan cerita pendek. Salah satu cerpen yang memiliki karakter tersebut diatas adalah cerpen dari seorang etnis Yahudi yang ingin sedikit mengulas realita kehidupannya di Amerika Serikat. Cerpen yang mengusung tema sisi kelam etnisnya, berjudul "Reaching For The Sky" karya Mitchell Waldman

Cerpen ini berkisah tentang hidup seorang Ibu dari etnis Yahudi yang tinggal di New York. Sebagai seorang kaum Ghetto, Betty Porter, harus menerima kenyataan bahwa dia dan mayoritas kaum minoritas yahudi menjadi kaum terpinggirkan. Kematian anaknya, Noah yang meninggal karena tabrak lari, tidak lama setelah adiknya, Bradley menjadi lumpuh karena di tembak oleh salah satu anggota gangster. Kehidupan yang sangat berat, baik dari sisi kehidupan sosial dan ekonominya, membuatnya putus asa. Sebagai seorang single parent menjadi seorang pramuniaga toko adalah hal yang sangat membuat hidupnya semakin terhimpit, terlebih sejak kematian Noah dan lumpuhnya Bradley. Hanya anganangan untuk memiliki kehidupan yang lebih baik yang membuatnya kembali bersemangat disela-sela keputus asaan dari tangisnya. 
Mitchell Waldman, seorang bangsa Yahudi lahir diera limapuluhan, di Chicago, Illinois. Seorang penulis karangan fiksi yang beraliran realis dan menyukai dialog yang sesuai dengan karakternya. Penulis dari kumpulan cerita pendek baru, Petty Offenses dan Crimes of the Heart (Wind Publications, 15 Agustus 2011) yang terpilih menjadi "Reviewer's Choice" (Penulis Resensi Pilihan) oleh Midwest Book Review, sebagai "Orang Terkemuka" oleh Newpages.com, dan mendapat penghargaan "Pushcart Prize nominated story", "The Duke of Broad Street," dan pemenang pertama "the 13th Story First Prize winning "Glass Slippers.

Selain menulis cerpen, Waldman juga mempersembahkan novel-novel, seperti $A$ Face in the Moon (Writers Club Press, 2000), sebuah cerita yang tidak mudah dilupakan oleh pembacanya dan kisah yang dalam secara emosional membuat pembaca masuk kedalam rasa sepi, pembaca muda yang sedih akan menahan nafas dan tidak bisa keluar dari alur cerita hingga buku selesai dibaca. Waldman sangat hebat dalam mengembangkan dan merefleksikan karakter dan sangat sesuai dengan realitas yang ada.

Sajak, essai termasuk cerpen Waldman berpusat pada bagian besar dari kehidupan sekarang ini, percintaan, perceraian dalam rumah tangga, dan fenomena sosial yang ada . Sisi lain dari karyanya yaitu menyangkut efek pasca perang dalam kehidupan berkeluarga, alienasi, atau yang lebih spesifik lagi bagaimana menjadi seorang Yahudi didalam komunitas luas masyarakat Nasrani. Cerpen Reaching For The Sky mewakili fenomena yang terjadi dan dialami oleh kaum minoritas (The Ghetto) Yahudi yang tinggal di Brooklyn, New York, AS. Dalam cerita ini seakan Waldman ingin membuka wacana terhadap apa yang terjadi didalm kehidupan social etnis Yahudi di Amerika. Secara gamblang dan lugas ia menyatakan ideologinya melalui tokoh-tokoh rekaan yang dimunculkannya. Kisah ini kemungkinan besar sangat menyentuh hati para pembacanya, bahkan dapat memberikan sumbangsih untuk mata dunia untuk lebih memberikan empatinya kepada kaum Yahudi di AS.

Rumusan masalah yang diperoleh adalah bagaimana Strukturalime Genetik ditunjukkan untuk kajian cerita pendek Reaching For The Sky?. Tujuan penulisan ini adalah untuk menunjukkan deskripsi hubungan strukturalistik genetik, ditunjukkan dalam kajian cerpen Reaching For The Sky. Tujuan penulisan dengan dilaksanakannya penelitian ini adalah: untuk mendeskripsikan hubungan strukturalistik genetik yang ditunjukkan dalam kajian cerpen Reaching For The Sky. 
Karya Ilmiah dibuat dengan tujuan dapat memberikan manfaat serta bisa menghasilkan sesuatu yang lebih baik, demikian dengan tulisan ini dapat memberikan sumbangsih di masa depan. Manfaat yang dapat diambil adalah:

1. Kegunaan Teoritis

a. Menjadi sumber masukan untuk memperkaya ilmu dan pustaka bagi semua pihak terutama untuk ranah penelitian dengan obyek yang dibedah dengan menggunakan teori strukturalisme genetik.

b. Sebagai sarana tambahan informasi yang tepat untuk penelitian selanjutnya dengan materi Strukturalime Genetik, terutama tentang penelitian cerpen Reaching For The Sky

\section{Fungsi Praktis}

a. Memperkaya wawasan dan sekaligus wacana dimasyarakat, yang difokuskan pada strukturalime genetik dan ditunjukkan dalam kajian cerpen Reaching For The Sky

b. Sebagai masukan bagi penulis di ranah susastra tentang pemahaman strukturalime genetik ditunjukkan dalam kajian cerpen Reaching For The Sky.

Penulisan ini menggunakan kerangka penulisan, diantaranya adalah:

1. Strukturalisme Genetik

Goldmann dalam Faruk menyatakan bahwa teori strukturalisme genetik adalah struktur dari sebuah karya sastra, yaitu sebuah struktur dinamis yang merupakan hasil dari rangkaian kisah - kisah masa lalu yang menjadi sejarah dan terus berlanjut hingga sekarang. Perpaduan strukturisasi dan destrukturisasi yang masih ada didalam masyarakat asli karya sastra tersebut dibuat.

Untuk menopang teorinya, menurut Goldmann dalam Faruk (2010:56), strukturalisme genetik adalah susunan dari rangkaian kelompok teori yang saling erat hubungannya.. Kelompok teori tersebut adalah fakta kemanusiaan, adanya subjek kolektif, strukturasi,suatu pandangan dunia, pemahaman dan penjelasan yang tepat.

\section{The Ghetto (Kaum Minoritas Di Bradley New York)}

Karya, terutama karya sasta memiliki suatu esensi untuk mengubah pandangan dunia terhadap sesuatu yang awalnya tidak mendapatkan atensi, kemudian tersorot menjadi sebuah hal viral. Sebuah karya adalah aspirasi dari pengarang yang mengamati dan ingin mengangkat suatu obyek, obyek yang menjadi akar dari tulisan pengarang adalah "the 
Ghetto”, terutama yahudi. Banyak karya yang ia ciptakan Mitchell Wattman untuk mengikis penganut pandangan strata sosial yang menimpangkan hak - hak kaum minoritas.

3. Definisi konsepsional

Dalam melakukan penelitian diperlukan suatu batasan dengan tujuan agar tidak terjadi miskomunikasi dan kesalahahpahaman dalam menemukan gambaran yang tepat mengenai permasalan yang sedang diteliti di lapangan.

Peneliti perlu memberikan penjelasan yang tepat tentang beberapa istilah yang digunakan dalam judul tulisan ini, dengan maksud agar akan muncul pemahaman yang tepat . Istilah yang digunakan dalam tulisan ini yaitu :

1. Strukturalisme Genetik

Menurut Ratna (2004:123) struktural genetik adalah analisis struktur untuk asal dari karya sastra, dan didukung dengan konsep baru yang tidak ditemukan dalam teori sosial yang sudah ada, contohnya adalah teori kelas-kelas sosial, subjek transindividual,simetri atau homologi juga tentang pandangan dunia

\section{The Ghetto}

Suatu kelompok yang hidup di sebuah kota besar, memiliki kelas sosial yang rendah dan selalu menjadi pihak yang dikucilkan, diremehkan dan seringkali menjadi sasaran bullying kelompok lain. The Ghetto dan hanya menjadi masyarakat minoritas.

Peneliti menggunakan beberapa landasan teori sebagai acuan untuk melanjutkan penelitian. Penulis menggunakan teori sosiologi sastra, pendekatan tentang kelas sosial, dan juga memasukan teori strukturalisme genetik untuk mencari pencerahan sebuah karya sastra.

\section{Sosiologi Sastra}

Sosiologi sastra bermula dari istilah sosiologi dan sastra. Sosiologi dari kata sos (Yunani) artinya bersama, bersatu, kawan, teman, dan logi (logos) dimaknai sebagai sabda, perkataan, perumpamaan. Sastra dari sas (Sansekerta) bermakna mengarahkan, mengajarkan, memberi petunjuk dan instruksi. Sufiks tra berarti alat, sarana. Dapat dipahami bahwa keduan kata tersebut mengarah pada obyek yang similar yaitu manusia dan masyarakat. Namun secara keseluruhan keduanya diametral, karena pada dasarnya diferensiasi antara sosiologi dan sastra sangat terlihat dari obyeknya.

Menurut Ratna (2003:2) terdapat pengertian dari sosiologi sastra yang perlu dipikirkan agar didapatkan keakuratan pemahaman korelasi antara karya sastra dengan 
masyarakat, pemahaman yang diharapkan tersebut antara lain: 1) pemahaman terhadap karya sastra disertakan pula aspek yang mendukung kemasyarakatannya; 2) pemahaman terhadap bagaimana karya dapat dimaksimalkan dengan memasukkan aspek kemasyarakatan didalamnya; 3) pemahaman bagaimana karya sastra itu sendiri dan sekaligus timbal baiknya dengan masyarakat yang menjadi latar belakang terciptanya karya; 4) Hubungan dua arah (dialektik) tentang sastra dengan masyarakat yang disebut dengan sosiologi sastra; dan 5) sosiologi sastra adalah suatu ilmu yang berusaha menemukan hubungan keterkaitan sastra dan masyarakat.

Wellek dan Warren (1956: 84, 1990:111) dalam bukunya menyatakan, bahwa sosiologi pengarang, profesi pengarang, dan institusi sastra merupakan dasar perekonomian produksi sastra, latar belakang (status sosial) pengarang, ideologi pengarang yang dapat dilihat dari kegiatan pengarang diluar karya sastranya,setiap pengarang adalah warga masyarakat. Pengarang berperan sebagai makhluk sosial. Sumber utama dari informasi pengarang adalah biografinya, selain mengetahui pengarang secara keseluruhan, dapat meluas ke domisili dan tanah air pengarang. Keseluruhan tentang diri pengarang, baik informasi mengenai tentang latar belakang keluarga, perekonomian pengarang sangat berguna untuk membedah tentang sosiologi pengarang (Wellek dan Warren, 1990: 112).

\section{Pendekatan Tentang Kelas Sosial}

Karl Marx menyatakan bahwa, kelas - kelas sosial adalah seluruh pemeran utama dari perilaku masyarakat yang ada. Marx juga menuturkan didalam karya Manifesto Komunisnya, sejarah perjuangan kelas merupakan sejarah manusia, akan terjadi sebuah penindasan antar kelas, dengan menggunakan cara apapun kelas yang 'tinggi' akan memenangkan diri mereka atas kelas yang 'rendah. Oleh sebab itu, perjuangan kelas mutlak diperlukan demi penghapusan penindasan dalam bentuk apapun. Tetapi teori ini tidak mendapat pencerahan secara jelas, dikarenakan Marx tidak menguraikan pemikirannya tentang teori ini melalui pemikiran teoritis lainnya, hanya tersirat saja.

Secara harfiah, kelas sosial adalah suatu kelompok masyarakat,dengan ketentuan khusus. Lenin mengungkapkan bahwa, kelas sosial diakui menjadi suatu kumpulan sosial dalam struktur masyarakat tetapi memiliki posisi spesifik didalam proses produksi. Marx menyatakan bahwa suatu kelas sosial adalah indikasi khusus dari masyarakat feodal,masyarakat dengan tipe ini memiliki pandangan bahwa kelompok atau individu 
Oryza Nurmartanti, Analisis Tentang Hubungan Antara Cerpen Reaching For The Sky Karya Mitchell Waldman dengan Teori

Strukturalisme Genetik

memiliki tingkatan tertentu di masyarakat, kelompok yang berbeda dalam masyarakat,mempunyai tujuan tertentu untuk diupayakan.

Karl Marx juga menyatakan, faktor utama dari peralihan sosial bukan pada perorangan, tetapi melalui kelas sosial. Fokus utamanya yaitu sistematika kewenangan ketika berinteraksi dengan kelompok, akan muncul kelas-kelas yang memiliki wewenang dan ada kelas-kelas yang menjalankan perintah dari yang berkuasa.

3. Penerapan Teori Strukturalisme Genetik Pada Karya Sastra

Goldmann dalam Faruk mengungkapkan bahwa strukturalisme genetik adalah sebuah teori untuk karya sastra yang mengandung struktur, yaitu sebuah struktur dinamis (bukan statis), artinya adalah karya sastra adalah hasil dari rangkaian kisah - kisah masa lalu yang menjadi sejarah dan terus berlanjut hingga sekarang. Perpaduan strukturisasi dan destrukturisasi yang masih ada didalam masyarakat asli karya sastra tersebut dibuat

Untuk menopang teorinya, Goldmann dalam Faruk (2010:56), membuat serangkaian klasifikasi yang saling terhubung dan menjadi sebuah teori strukturalisme genetik. Klasifikasi yang dimaksud adalah fakta kemanusiaan, subjek kolektif, strukturasi, pandangan dunia, pemahaman dan penjelasan.

Acuan pertama dari strukturalisme genetik yaitu fakta kemanusiaan. Fakta kemanusiaan adalah hasil tindakan manusia atau sikap manusia yang dilakukan secara fisik dan verbal,dan dianalisis menggunakan pengetahuan. Fakta yang tercipta melalui segala kegiatan sosial yang spesifik, dunia politik tertentu, maupun pengembangan kreasi kebudayaan, diantaranya adalah filsafat, kesenian dan sastra. Kesemuanya membentuk rangkaian - rangkaian kelompok berkorelasi menjadi bentuk strukturalisme genetik. Klasifikasi tersebut yaitu fakta kemanusiaan, subjek kolektif, strukturasi, pandangan dunia, pemahaman dan penjelasan.(Goldmann dalam Faruk, 2010:56)

Goldmann menyatakan bahwa perilaku yang ditunjukkan adalah usaha manusia untuk mengubah dunia, demi mendapatkan kesetaraan yang baik antara manusia (sebagai subjek) dan dunia. Perilaku manusia ini sarat makna karena terbentuk suatu perbaikan keseimbangan (equilibrium) (Goldmann 1981:40)

Faruk menyatakan bahwa produk dari aktifitas manusia sebagai subjek adalah penjabaran dari fakta kemanusiaan, subjek yang cocok dengan fakta yang dihasilkan yaitu subjek individual dengan hasilnya berupa fakta individual (libinal) dan suatu subjek kolektif yang memberikan sebuah fakta sosial (historis) (Faruk 2009:14) 
Oryza Nurmartanti, Analisis Tentang Hubungan Antara Cerpen Reaching For The Sky Karya Mitchell Waldman dengan Teori Strukturalisme Genetik

Strukturalisme genetika memandang subjek kolektif sebagai bagian signifikan pemicunya adalah adanya indikasi dari subjek kolektif dapat menghasilkan karya-karya kultural yang besar dan dijadikan topik utama dalam karya sastra, faktor - faktor tersebut adalah revolusi sosial, politik dan ekonomi (Faruk,2009:14-15). Teori Goldmann juga menyebutkan bahwa subyek trans-individual membentuk fakta-fakta sosial (Goldmann 1971:97), subjek trans-individual adalah suatu kesatuan, suatu kolektifitas dan bukan bentuk dari individu-individu yang berdiri sendiri(Faruk 2009:15).

Pandangan dunia adalah persepsi visual yang seimbang mengenai manusia sebagai makhluk sosial dan keserasiannya dengan alam semesta (Goldmann, 1970: 111). Pandangan dunia itu sendiri adalah fakta historis dan sosial, yang merupakan keseluruhan ideologi, rasa dan aksi dimana pada situasi tertentu membuat manusia menemukan diri pada kondisi ekonomi dan sosial setara dengan kelompok sosial tertentu. Pandangan dunia direalisasikan dengan proses tertentu, menggunakan peran fakta sosial yang berasal dari interaksi antara subjek kolektif dengan sekelilingnya,. Perubahan mentalitas yang butuh proses perlahan dan bertahap dibutuhkan demi terciptanya bentuk mentalitas yang baru (Faruk, 2009:16; Goldmann, 1970: 112).

Maha karya sastra adalah pencapaian dari strukturasi subjek kolektif, memiliki strukturasi koheren dan paduan sesuai dengan pandangan strukturalisme genetik. Goldmann menyatakan bahwa karya sastra merupakan ungkapan ekspresif imajinatif pandangan pengarang sepenuhnya menciptakan secara imajiner dunia dan karakter karakter, objek dan relasi. Bagi Goldmann, poin tersebut adalah suatu pembeda suatu karya sastra sengan filsafat ataupun sosiologi (Faruk 2009: 17).

Dengan demikian, dapat diketahui bahwa Goldmann memusatkan pemikirannya pada suatu relasi tokoh satu dengan tokoh lainnya dan antara tokoh dengan lingkungan sekitarnya. Goldmann juga menyatakan didalam tulisannya yang berjudul The Sociology of Literature: Status and Problem of Method, bahwa sebagian besar karya penelitian Goldmann berpusat pada satu bentuk kesatuan, untuk membuka koherensi dan keterpaduan yang membentuk susunan karya sastra secara keseluruhan (Faruk, 2009: 17).

Pandangan strukturalisme genetik memberikan kesan bahwa karya sastra adalah struktur koheren yang bermakna. Goldmann mengembangkan sebuah metode yang bertujuan memahami makna, metode tersebut adalah metode dialektik. Hal mendasar pada metode dialektik berhubungan koherensi tersebut, adalah pemahamannya tentang 
bagaimana memaknai keabstrakan bentuk fakta kemanusiaan apabila tidak dibuat konkret dengan menyatukannya pada keseluruhan. Pengembangan metode dialektik terdapat pada dua pasangan konsep yaitu "keseluruhan-bagian" dan "pemahaman-penjelasan" (Faruk, 2009: 19-20).

Dalam pandangan Faruk, pandangan dialektik, tidak memiliki titik awal mutlak dan tak ada persoalan yang secara keseluruhan yang terselesaikan. Setiap ide individual menjadi bermakna apabila diletakkan dalam keseluruhan, sedangkan keseluruhan hanya dapat dimengerti ketika fakta-fakta parsial bertambah, keseluruhan tidak akan dapat dipahami tanpa bagian, dan bagian tidak dapat diterjemahkan tanpa keseluruhan (Faruk, 2009:20).

Dari segi struktur,karya sastra merupakan potongan - potongan kecil. Proses identifikasi akan membantu kita memahami apa sebenarnya karya tersebut. Sedangkan teks dalam sastra adalah bagian dari keseluruhan pada porsi yang lebih besar yang akhirnya menjadi struktur sarat makna. Untuk pemahamannya diperlukan suatu usaha untuk proses penjelasan dan memposisikannya dalam keseluruhan lebih besar. Jadi didapatkan konsep dialektika yang sebenarnya, "pemahaman-penjelasan”.Pemahaman dapat diartikan sebagai cara untuk memahami identitas bagian, penjelasan itu sendiri yaitu suatu cara untuk mencerna makna itu dengan memposisikannya dalam keseluruhan yang lebih besar.

\section{Metode Penelitian}

Peneliti menggunakan metode deskriptif analisis dengan menggunakan teknik analisis sebagai teknik analisis data. Menurut Ratna (2012:53) deskriptif adalah penguraian karya sastra atas unsur-unsurnya dengan cara mendeskripsikan fakta - fakta dilanjutkan dengan penguraian dan memberi suatu pemahaman juga penjelasan yang cukup. Ratna dalam Ridwan Fauzi (2012) menyatakan bahwa metode deskriptif adalah cara yang diambil untuk melakukan penelitian pada suatu kelompok orang,suatu objek dan suatu keadaan, system gagasan dan peristiwa masa kini. Metode ini digunakan dengan teori positivistik, yang menitikberatkan pada teks sastra,dimana positivistik, saling menekankan pada teks sastra.Disisi lain, positivistik tidak memperhitungkan koherensi struktural.

Untuk memperoleh teori-teori dan data-data yang relevan dengan penelitian yakni berupa strukturalistik genetik melalui cerpen Reaching For The Sky penulis menggunakan metode studi pustaka, menggunakan teknik pengumpulan data dan sekaligus teknik dokumentasi. 
Arikunto (2010:158 ) menyatakan teknik dokumentasi digunakan untuk mendapatkan dan menyimpankan data mengenai hal-hal yang diperlukan, antara lain adalah mencatat, transkrip, buku, surat kabar, majalah, notulen, rapot, agenda dan lain lain. Teknik tersebut dipergunakan untuk mengumpulkan segala informasi berkaitan dengan strukturalistik genetik melalui cerpen Reaching For The Sky

Hasil analisis data yaitu berisi paparan tentang segala hal yang dimaksud agar penjelasan tentang kaidah yang ditentukan lebih terperinci dan terurai. Hasil analisis data dilakukan secara deskriptif dengan menggunakan kata atau ucapan atau penuturan lisan dalam cerpen dan tidak menggunakan lambang. Hasil analisis data yaitu penerapan teori strukturalistik genetik yang disajikan melalui cerpen Reaching For The Sky.

\section{Hasil dan Pembahasan}

Pembasan tentang hubungan dua arah (dialektik) diranah sastra dan keterkaitannya dengan masyarakat.(Ratna,2003:12). Cerpen sindiran, sebuah kritik dan merupakan bentuk opini terhadap strata sosial yang ada di Amerika Serikat terutama di Brooklyn, New York. Terlihat disini bahwa penduduk pendatang selain kalangan kulit putih, terutama etnis minoritas (the Ghetto) yang hidup di garis kemiskinan, tidak pernah mendapatkan "tempat" dilingkungan sosial New York.

Reaching For The Sky, merupakan bentuk cerpen yamg ditujukan untuk menyajikan sebuah realita kehidupan di masyarakat, ingin menyampaikan sebuah pesan tentang adanya ketimpangan sosial yang dialami oleh segenap kaum Yahudi di Amerika Serikat. Kehidupan yang tidak makmur, berada digaris kemiskinan dan ketidakadilan yang diberikan dari sudut pandang manapun, membuat pengarang terinspirasi untuk membuat cerpen ini. Cerpen yang juga berbicara tentang adanya kelas sosial,terdiri dari kaum lemah dan kuat. Lemah secara ekonomi, sosial dan dalam sebagai warga Negara. Kuat baik secara ekonomi, hukum dan kuat dari berbagai sudut manapun.

Dalam cerpen ini, dapat jelas ditunjukkan keberadaan kaum lemah, yaitu kaum ghetto atau kaum minoritas Yahudi sebagai menempati masyarakat terpinggirkan di New York, seringkali mendapat kekerasan baik fisik maupu psikologis, ketidakadilan dalam kesetaraan sosial, hanya berperan kecil didalam masyarakat dan ketika ada the Ghetto yang sejahtera, tetap saja kenyamanan hidupnya terancam. Disisi lain, eksistensi dari warga Amerika kulit putih mendapatkan posisi yang baik dan kondusif. Hal yang dialami oleh the ghetto didalam cerpen ini salah satunya tersirat dari keluh Betty, seorang wanita paruh 
baya the ghetto, meratapi nasib kedua putranya yang menjadi korban dan salah satunya meninggal dunia dikarenakan sikap semena- mena dan ketidakadilan dari sikap masyarakat Brooklyn terhadap mereka. “...How could she explain it to him? It made no sense at all, nothing made any sense anymore. First him, and now Noah, killed only three months ago in a car crash. Noah, the one who had made it out of the ghetto, out of Brooklyn, out of New York." (Waldman :2012)

\section{Hubungan Teori Strukturalisme Genetik dalam Cerpen Reaching For The Sky}

\section{Fakta Kemanusiaan}

Rangkaian suatu proses sejarah yang terus berlangsung hingga sekarang adalah bagian dari struktur karya sastra. Masyarakat asal karya sastra hidup dan menghayati proses strukturisasi dan destrukturisasi, sehingga terbentuk suatu tatanan kategori yang erat hubungannya satu sama lain hingga muculnya strukturalisme genetik. Fakta kemanusiaan, subjek kolektif, strukturasi, pandangan dunia, pemahaman dan penjelasan adalah bagian dari kategori - kategori tersebut.(Goldmann dalam Faruk , 2010: 56).

Dalam kajian Cerpen Reaching For The Sky, terdapat suatu hubungan timbal balik antar manusia dan lingkungannya. Fakta kemanusiaan yang jelas dapat ditampakkan dari latar belakang pengarang cerpen menuangkan ide dan gagasan-gagasannya. Berlatar belakang seorang etnis Yahudi, menuliskan sebuah kisah cerita pendek tentang lingkungan minoritas Yahudi miskin yang kepayahan dalam bertahan hidup dalam lingkungan kelompok etnis yang mendominasi di Amerika yaitu kulit putih. Didalam kekalahan kaum minoritas, pengarang ingin menyampaikan seluruh pendapatnya melalui tokoh-tokoh yang diciptakannya, tokoh utama sebagai sentralisasi ide dan pemikiran pengarang. Disisi lain, tokoh-tokoh yang berpengaruh dalam kehidupan tokoh utama adalah perwujudan dari lemahnya kekuatan the ghetto untuk mengimbangi kekuatan kaum mayoritas. Pengarang seolah menunjukkan timbal balik, proses asimilasi dan akomodasi. Asimilasi yang di representasikan oleh pengarang cukup membuktikan bahwa manusia tidak mampu mengelakkan halangan-halangan yang menggagalkan proses asimilasi tersebut, sehingga mau tidak mau, manusia sebagai pejuang asimilasi harus menyatu dengan dunia luar yang lebih menguasainya. 
Oryza Nurmartanti, Analisis Tentang Hubungan Antara Cerpen Reaching For The Sky Karya Mitchell Waldman dengan Teori

Strukturalisme Genetik

"This was the place she had run to escape the fighting of her parents back in the bad old days of her youth, where she had run to when her mother had ended up in the hospital that time her dad had gotten too drunk and had come home accusing her, and flailing at her like a wild bear gone mad. It was where she had come when she was older, when Jimmy Dawkins had tried to touch her where he wasn't supposed to, and she'd wept hot tears onto the proud brown bark of this tree" (Waldman:2012).

\section{Subjek Kolektif}

Sebuah karya akan menjadi besar apabila menciptakan revolusi perubahan besar-besaran, pengarang, secara kontinyu menciptakan karya-karya baik fiksi maupun non fiksi untuk dapat menyalurkan aspirasinya agar terjadi sebuah perubahan besar-besaran terhadap the ghetto. Banyak karya yang ia ciptakan untuk mengikis penganut pandangan strata sosial yang menimpangkan hak-hak kaum minoritas.

\section{Pandangan Dunia}

Melanjutkan bahasan sebelumnya, Reaching For The Sky bertemakan sebuah pertentangan kelas sosial yang menciptakan ketidakadilan dan kaum minoritas yang menjadi pihak tersudut. Karya ini sangat mewakili suara dan ideologi kaum-kaum yang terpinggirkan. Tersusun disetiap kata, menyentuh hati dan dipublikasikan dengan misi menunjukkan pada masyarakat untuk mengetahui sisi dunia yang mungkin terlewatkan dan dijadikan sebuah topik pembicaraan menarik, pada akhirnya ada solusi bagi kepentingan bersama. Kutipan berikut adalah perwujudan dari sebuah ungkapan untuk membuka mata dunia terhadap kaum minoritas. "I was just sitting there and he shot me," that's what the note to the doctor said, months after the shooting, after Bradley'd remembered it. "He told me his friends were going to rob the man." That's what the newspaper columnist had said ( Waldman:2012).

\subsection{Struktur Karya Sastra}

Keunikan karya sastra adalah pada suatu fakta bahwa seluruh ideologi, kritik, sumbangsih dan hal lainnya yang sekiranya dapat menjadikan individu dan lingkungan menjadi terpengaruh, mengikuti falsafah-falsafah yang terdapat pada karya sastra tersebut yang dapat diciptakan melalui tokoh-tokoh imajiner. Cerpen Reaching For The Sky, tokoh rekaan yang diciptakan oleh pengarang dapat merepresentasikan kesemuanya dengan baik, mewakili semua yang menjadi opini dan ideologi pengarang. Contoh dari sebuah ideoleogi 
yang tersusun rapi dan terungkapkan dengan baik dalam diri seorang tokoh Betty Porter adalah sebagai berikut:

"No matter what you say, boy, it don't matter which way you go. You was just a boy then, maybe didn't know no better, or maybe did it just to go along with your friends. Maybe you was just being a boy from the ghetto, mad and tired of all the shit you had to take from the world, from the man. It wouldn't make it right, but it would help me some..." (Waldman:2012).

\subsection{Dialektika Pemahaman}

Dalam memahami konsep dialektika dalam pemahaman sebuah teks karya sastra, diperlukan sebuah kejelian untuk mengetahui sampai sedetail-detailnya bagian terkecil dari teks terasebut. Pemahaman untuk karya sastra cerpen Reaching For The Sky adalah: pembaca menangkap isi dan maksud dari pengarang menciptakan karyanya. Apakah karyanya mengandung sebuah pesan tertentu, yang harus dapat disampaikan dan aspirasikan dengan gaya yang lugas, diksi yang tepat namun mengena dan tepat sasaran. Berikut ini adalah cara Waldman mengusung tema pembelaannya terhadap the ghetto yahudi di New York beserta harapan dari pengarang menjadikan kehidupan the ghetto menjadi lebih baik dengan sikap pantang menyerah.

"She thought: I will be a tree, that's what I have to be. Then she spread her arms like branches in the oak's shadow, and stretched her fingers to the sky, to heaven. She stood tall like the dignified oak, her back erect, as the tears flooded her face. But beneath the tears, a smile grew as a new strength seemed to fill her now, and, standing stone still, she gazed..." (Waldman: 2012).

\section{Simpulan}

Cerpen Reaching For The Sky karya Mitchell Waldman adalah sebuah karya yang sarat akan kritik tentang ketimpangan kelas sosial yang terjadi di Brooklyn, New York, AS. Cerpen ini selain mengusung tema tentang kelas sosial, dapat pula di kaji lebih mendalam menggunakan teori Strukturalisme Genetik. Hal ini dapat dicapai karena antara cerpen dan pengarangnya, terdapat suatu keterkaitan yang sangat erat. Dapat diidentifikasi melalui latar belakang pengarang dan apa saja yang ada didalam cerpen tersebut. Tokoh-tokoh, setting, alur cerita, cukup mewakilkan akan adanya korelasi cerpen, pengarang dan teoriteori yang mendukung adanya keterkaitan antara jalan cerita cerpen dan strukturalisme genetik. Keterkaitan tersebut dibentuk melalui Fakta Kemanusiaan, Subjek kolektif, pandangan dunia,strukturasi juga adanya sebuah dialektika pemahaman. 
Oryza Nurmartanti, Analisis Tentang Hubungan Antara Cerpen Reaching For The Sky Karya Mitchell Waldman dengan Teori Strukturalisme Genetik

\section{Daftar Pustaka}

Faruk, Dr. Pengantar Sosiologi Sastra: dari Strukturalisme Genetik sampai PostModernisme. Jakarta: Pustaka Pelajar, 2009.

Goldmann, Lucien. Method in the Sociology of Literature. Terj. William Boelhower. Oxford: Basil Blackwell, 1981.

Hakim,Lutpiyah,2013. "Pandangan Dunia Ali Ahmad Bakatsir Dalam Novel Sallamah AlQas Analisis Strukturalisme Genetik Lucien Goldmann”.Diakses melalui http://etd.repository.ugm.ac.id/index.php?act=view\&buku_id=58886\&mod=penelit ian_detail\&sub=PenelitianDetail\&typ=html, pada 27 Agustus 2019, pukul 14.56 WIB.

Homestead.com, 2019. "Mitchell Waldman Bio".Diakses melalui https://mitchwaldman.homestead.com/Bio.html, pada 26 Agustus 2019, pukul 21.25 WIB.

Leyna, Riki dan Erinn Durkin,2017. "Brownsville Is Brooklyn's Worst Neighborhood For Children Due To High Poverty, Lousy Access To Fresh Food And Day Care".Diakses melalui https://www.nydailynews.com/newyork/brooklyn/brownsville-brooklyn-worst-neighborhood-children-article1.3009978, pada 27 Agustus 2019, pukul 14.22 WIB.

Permata, Rocky,2011. "Teori Kelas Karl Marx”. Diakses melalui http://rockypermata.wordpress.com/2011/09/18/ ,pada 27 Agustus 2019,pukul 13.20 WB.

Ratna, Nyoman Khuta. 2003. Paradigma Sosiologi Sastra. Yogyakarta: Pustaka Pelajar.

Real Streetz, The.2019 “Brooklyn, Before They Gentrify”.Diakses melalui https://www.therealstreetz.com/2019/05/28/real-brooklyn-neighborhoods/, pada 27 Agustus 2019, pukul 14.01 WIB.

Waldman,Mitchell.2014."Reaching for the Sky". Diakses melalui http://www.fictionontheweb.co.uk/2014/10,pada 26 Agustus 2019, pukul 21.10 WIB.

Wikipedia, 2012 . Yahudi .Diakses melalui http://id.wikipedia.org/wiki/ pada 27 Agustus 2019, pukul 13.00 WIB. 